E3S Web of Conferences 1, 35002 (2013)

DOI: $10.1051 / \mathrm{e} 3$ sconf/20130135002

(C) Owned by the authors, published by EDP Sciences, 2013

\title{
Solidification and Immobilization of Heavy metals in Soil using with nano-metallic $\mathrm{Ca} / \mathrm{CaO}$ Dispersion Mixture
}

\author{
S. R. Mallampati ${ }^{1}$, Y. Mitoma ${ }^{1 *}, \underline{\text { T. Okuda }^{2 *}}$, S. Sakita $^{1}$ and M. Kakeda ${ }^{1}$ \\ ${ }^{1}$ Department of Environmental Sciences, Faculty of Life and Environmental Sciences, Prefectural University of \\ Hiroshima, 562 Nanatsuka-Cho, Shobara City, Hiroshima 727-0023, Japan \\ ${ }^{2}$ Environmental Research and Management Center, Hiroshima University, 1-5-3 Kagamiyama, Higashi-Hiroshima, \\ Hiroshima 739-8513, Japan \\ * Corresponding authors. (Y. Mitoma); Tel./fax:+818247 41748; E-mail addresses: mitomay@pu-hiroshima.ac.jp. (T. \\ Okuda) Tel./fax: +81 824246195; Email address: okudaenv@hiroshima-u.ac.jp.
}

\begin{abstract}
In the present work, the use of nano-metallic calcium $(\mathrm{Ca})$ and calcium oxide $(\mathrm{CaO})$ dispersion mixture for the immobilization of heavy metals ( $\mathrm{As}, \mathrm{Cd}, \mathrm{Cr}$ and $\mathrm{Pb}$ ) in soil was investigated. With simple grinding, $85-90 \%$ of heavy metals immobilization could be achieved, while it could be enhanced to $98-100 \%$ by grinding with the addition of nano-metallic $\mathrm{Ca} / \mathrm{CaO}$ dispersion mixture. By SEM-EDS elemental maps as well as semi-quantitative analysis observed that the amount of $\mathrm{As}, \mathrm{Cd}, \mathrm{Cr}$ and $\mathrm{Pb}$ measurable on soil particle surface decreases after nano-metallic $\mathrm{Ca} / \mathrm{CaO}$ treatment. The leachable heavy metals concentrations were reduced, to the concentration lower than the Japan soil elution standard regulatory threshold, i. e., $<0.01 \mathrm{mg} / 1$ for $\mathrm{As}, \mathrm{Cd}$ and $\mathrm{Pb}$ and $0.05 \mathrm{mg} / 1$ for $\mathrm{Cr}$. Whereas, the effect of soil moisture and $\mathrm{pH}$ on heavy metals immobilization was not much influenced. The results suggest that nano-metallic $\mathrm{Ca} / \mathrm{CaO}$ mixture is suitable to be used for the gentle immobilization of heavy metals contaminated soil at normal moisture conditions.
\end{abstract}

Key words: Solidification, immobilization, heavy metals, soil grinding, nano-metallic $\mathrm{Ca} / \mathrm{CaO}$.

\section{Introduction}

The remediation of contaminated soils follows a rapid upward trend in Japan, especially after the Soil Contamination Countermeasures Law proclamation in 2002 and enforcement in 2003 (Ministry of Environment Government of Japan, 2002). Heavy metals contaminated sites pose a serious hazard to public health and the environment. Heavy metal contaminated soils are notoriously hard to remediate. Hence, its remediation is recognized to be one of the most difficult problems to be solved by taking advantage of suitable technologies.

Typical remediation techniques for heavy metals in soil are constituted by extraction and immobilization processes. Extractive techniques may involve inorganic acids or organic acids and surfactants (Macauley and Hong, 1995). Ex-situ extractive technologies are rarely adopted because of high risks and costs related to the use of hazardous extractants, the consequent need of treating secondary wastewater and shortage of landfill sites. On the other hand, in-situ extractive technologies are constituted mainly by phytoextraction and electrokinetic extraction (Reddya et al., 2001). Phytoextraction, may require extremely long times. The efficiency of electrokinetic extraction, may be strongly affected by soil type and contaminant species to be removed. Considering the limitations of the extractive techniques described above, immobilization processes are generally preferred for treating heavy metal contaminated soils (Paff and Bosilovich, 1995). Immobilization is typically performed by mixing the contaminated soil with suitable binders, which are able to reduce heavy metals leachability through $\mathrm{pH}$ and alkalinity control to minimize their solubility, or by increasing adsorption, ionic exchange and precipitation of pollutants (USEPA, 1982). A variety of binders were investigated to immobilize heavy metals in soils. Mainly with hydroxyapatite, zeolites, calcium hydroxide and phosphates. On the other hand, cement based stabilization/solidification treatment process for immobilizing hazardous substances that contain heavy metals is well known (Lin et al., 1998). Unfortunately, these immobilization treatment process are wet condition, the use of cement is expensive, forming of secondary effluents and their treatment for additional cost are the main drawbacks. Therefore, the treatment under dry and water free conditions should be considered. While, our 
recent investigations showed that the nano-metallic $\mathrm{Ca} / \mathrm{CaO}$ mixture was the most effective for hydrodechlorination about $98 \%$ of PCDDs, PCDFs and PCBs in contaminated fly ash, and also, for cesium immobilization about $96 \%$ in soil by ball milling treatment (Mitoma et al., 2011; Srinivasa Reddy et al., 2012). The high PCDDs, PCDFs and PCBs hydrodechlorination and cesium immobilization with the addition of nano-metallic $\mathrm{Ca} / \mathrm{CaO}$ may be caused by the high reduction potentials and high surface area produced by ball milling. Whereas, in case of cesium immobilization, $\mathrm{Ca} / \mathrm{CaO}$ and sodium phosphate $\left(\mathrm{NaH}_{2} \mathrm{PO}_{4}\right)$ can also make immobile salts with moisture and $\mathrm{CO}_{2}$ in atmosphere, including pozzolanic cement and hydraulic property, cesium would be brought into the immobile $\mathrm{Ca} / \mathrm{PO}_{4}$ salts (Srinivasa Reddy et al., 2012). We assumed, that the addition of the nano-metallic $\mathrm{Ca} / \mathrm{CaO}$ would effectively reduce the heavy metal leaching potential from contaminated soil by its high reduction potential and high surface area with simple grinding. Therefore, in the present work, the use of nano-metallic $\mathrm{Ca} / \mathrm{CaO}$ dispersion mixture for the immobilization of heavy metals (As, $\mathrm{Cd}, \mathrm{Cr}$ and $\mathrm{Pb}$ ) in contaminated soil was investigated by simple grinding process. The degree of metal immobilization was evaluated by analyzing the leachable fraction of heavy metals obtained through the application of the Japanese soil elution standards. Furthermore, the effect of soil moisture and $\mathrm{pH}$ on heavy metals immobilization and the mechanism was also studied.

\section{Materials and Methods}

Heavy metals contaminated soil was synthetically prepared in laboratory having different moisture content, 1,5 and $10 \%$. One thousand $\mathrm{mg} / \mathrm{L}$ of heavy metal (As, $\mathrm{Cd}, \mathrm{Cr}$ and $\mathrm{Pb}$ ) standard solutions was thoroughly mixed on $1 \mathrm{~kg}$ of sandy soil (non-polluted, commercially available mica/isinglass/fibrolite soil type, produced in Okayama prefecture, Japan). While, nano-metallic $\mathrm{Ca} / \mathrm{CaO}$ (dry system) was prepared with metallic $\mathrm{Ca}$ and $\mathrm{CaO}$ through planetary ball milling process. Granular particles of metallic calcium was purchased from Kishida Chemical Co. Ltd. (99\%, particle size distribution: 2.0-2.5 mm, surface area: $0.43-0.48 \mathrm{~m}^{2} / \mathrm{g}$ ). Fine grade $\mathrm{CaO}$ was also commercially obtained with $98 \%$ purity from Kishida Chemical Co. Ltd. Room temperature under Argon (Ar) gas atmosphere, metallic $\mathrm{Ca}$ and dry $\left(825^{\circ} \mathrm{C}\right.$ for $2 \mathrm{~h}) \mathrm{CaO}$ composition $(\mathrm{Ca} / \mathrm{CaO}=2 / 5)$ were introduced in the planetary ball mill (Retsch PM-100; 20 pieces SUS, $32 \mathrm{~g} / \mathrm{ball}$ ). Stirring was carried out for $1 \mathrm{hr}$ at $600 \mathrm{rpm}$ to a rotation-to-revolution ratio of 1 to 2 . After stirring samples were collected in glass bottles, Ar gas was filled and stored to be used further treatment experiments. The maximum particle size distribution was observed at 263 nm. Heavy metal contaminated soil was grinded using a magnetic grinder (AS ONE) at 100-150 rpm in a ceramic vessel at room temperature for 6 hours under air, together with dry nano-metallic $\mathrm{Ca} / \mathrm{CaO}$ dispersion mixture (1.00/0.11 (synthetically prepared heavy metal contaminated soil/nano-metallic $\mathrm{Ca} / \mathrm{CaO})$ ).

After treatment without and with addition of nano-metallic $\mathrm{Ca} / \mathrm{CaO}$, the soil mixture was cooled to room temperature and performed soil elution test according with standard methods (Ministry of Environment Government of Japan, 2003). In order to determine the $\mathrm{pH}$ effect on immobilization efficiency, during the elution test with nano-metallic $\mathrm{Ca} / \mathrm{CaO}$ treated soil sample solutions $\mathrm{pH}$ was also adjusted to $\mathrm{pH} 7$ with concentrated $\mathrm{HCl}$. Heavy metal concentrations in eluted solutions were measured using Inductively Coupled Plasma Optical Emission Spectrometry (ICP-OES; Varian, 720-ES). These experiments were repeated three times, giving similar results.

In order to elucidate immobilization mechanisms and to verify if soil alterations occurred during the treatment, the metals mapping analysis on the soil surface conducted. Scanning electron microscopy combined with electron dispersive spectroscopy (SEM-EDS; JEOL, JSM6510A equipped with a $\mathrm{Si}$ (Li) probe with a resolution of $138 \mathrm{eV}$ ) microanalysis and semi-quantitative analysis were carried out with SEM-EDS in order to analyze $\mathrm{As}, \mathrm{Cd}, \mathrm{Cr}$ and $\mathrm{Pb}$ distribution within the solid matrix. Generally, EDS could detect the fluorescent X-ray from the surface layer until $10 \mu \mathrm{m}$ depth. On the other hand, X-ray diffraction (XRD) analyses were also performed in order to identify crystalline phases on the surface of solid samples, and it was carried out using a RIGAKU, RINT XRD by employing $\mathrm{CuK} \alpha$ Ni-filtered radiation $(\lambda=15.418 \AA)$. $\mathrm{X}$-ray diffraction data were collected for values of $2 \theta$ between $10^{\circ}$ and $90^{\circ}$.

\section{Results and Discussion}

With nano-metallic $\mathrm{Ca} / \mathrm{CaO}$ addition, after grinding, the concentration of heavy metals released in the leachate significantly decreased. While, these eluted heavy metals efficiency in the soil ( $1 \%$ moisture content) corresponds only to $0.02-3.8 \%$ (Fig. 1). Similar results were also observed with soil $5 \%$ and $10 \%$ moisture and at different $\mathrm{pH}$ conditions. Although, different soil moisture content and $\mathrm{pH}$ had revealed very slight, about $1 \%$, variation on As, $\mathrm{Cd}, \mathrm{Cr}$ and $\mathrm{Pb}$ immobilization efficiency. It was clearly observed that leachable heavy metal substantially decreases after nano-metallic $\mathrm{Ca} / \mathrm{CaO}$ mixture treatment to lower than the soil leachate regulatory standard limits $(<0.01 \mathrm{mg} / 1$ for $\mathrm{As}, \mathrm{Cd}$ and $\mathrm{Pb}$ and $0.05 \mathrm{mg} / 1$ for $\mathrm{Cr}$ respectively) proposed by Japan soil elution standard regulatory threshold.

By SEM microstructure analysis, blending the heavy metals contaminated soil with nano-metallic $\mathrm{Ca} / \mathrm{CaO}$ decreased the production and development of the core particles and would be caused the hydration products to coat the aggregates extremely. This fact probably indicates that a certain amount of heavy metals was entrapped inside new aggregates produced during the nano-metallic $\mathrm{Ca} / \mathrm{CaO}$ treatment. Furthermore, from SEM-EDS 3D elements maps, it is also possible to 
observe that, the amount of $\mathrm{Cd}, \mathrm{Cr}$ and $\mathrm{Pb}$ detectable on the soil particle surface decreases after nano-metallic $\mathrm{Ca} / \mathrm{CaO}$ treatment (Fig. 2). On the other hand, Ca mass percent increased. The reduction of $\mathrm{As}, \mathrm{Cd}, \mathrm{Cr}$ and $\mathrm{Pb}$ amount on soil particle surface is a possible explanation for increase of immobilization efficiency with nano-metallic $\mathrm{Ca} / \mathrm{CaO}$ treatment, by enclosed/bided soil surface with $\mathrm{Ca}$ associated compounds. Furthermore, XRD analysis the major phases identified in soil before treatment was quartz and clay minerals kaolinite and bentonite. When the same soil was subjected to grinded with nano-metallic $\mathrm{Ca} / \mathrm{CaO}$ peaks related to $\mathrm{Ca}$ crystalline phases $\left(\mathrm{CaCO}_{3} / \mathrm{Ca}(\mathrm{OH})_{2}\right)$ appeared in addition to quartz, kaolinite and bentonite. This probably indicates that main amount of enclosed/bided materials was $\mathrm{Ca}$ associated complexes.

The most probable mechanism for the enhanced heavy metals immobilization capacity with nano-metallic $\mathrm{Ca} / \mathrm{CaO}$ treatment may be probably ascribed to phenomena such as adsorption and entrapment of heavy metals into new formed aggregates due to prompting aggregation of soil particles and enclosed/bided with $\mathrm{Ca}$ associated immobile salts as schematically shown in Fig. 3. It is possible to assume that when soil is contaminated, heavy metals is adsorbed onto soil particles (Fig. 3a) through a surface coordination process. During grinding in the presence of nano-metallic $\mathrm{Ca} / \mathrm{CaO}$, soil particles are subjected to collisions that may promote aggregation and breakage phenomena as well as accumulation of crystalline defects and vacancies amorphization (Montinaro et al., 2007). When aggregation occurs in the presence of nano-metallic $\mathrm{Ca} / \mathrm{CaO}$, the amount of heavy metal adsorbed on the surface of two overlapping particles may be entrapped within the new formed aggregates (Fig. 3b). Moreover, it is also possible to assume that heavy metal complexes may diffuse within the crystalline reticulum of soil particles thus leading to a very efficient chemical entrapment of heavy metal within the soil in presence of nano-metallic $\mathrm{Ca} / \mathrm{CaO}$. On the other hand, nano-metallic $\mathrm{Ca} / \mathrm{CaO}$ could make immobile salts with moisture and $\mathrm{CO}_{2}$ in atmosphere, including pozzolanic cement and hydraulic property, hence heavy metals (As, $\mathrm{Cd}, \mathrm{Cr}$ and $\mathrm{Pb}$ ) would be brought into the immobile $\mathrm{Ca}$ salts, therefore, the surfaces of soil might enclosed/bided with $\mathrm{Ca}$ associated $\left(\mathrm{CaCO} 3 / \mathrm{Ca}(\mathrm{OH})_{2}\right)$ salts (Fig. 3b). In this way, the amount of heavy metals exposed to the leaching accomplishment is reduced thus determining a enhanced immobilization capacity with nano-metallic $\mathrm{Ca} / \mathrm{CaO}$ treatment. These results appear to be promising and the simple grind with nanometallic $\mathrm{Ca} / \mathrm{CaO}$ addictive may be considered potentially applicable for the remediation of heavy metals contaminated soil.

\section{Conclusions}

With simple grinding, $85-90 \%$ heavy (As, $\mathrm{Cd}, \mathrm{Cr}$ and $\mathrm{Pb}$ ) metals immobilization could be achieved in soil, and enhanced about $98-100 \%$ of heavy metals immobilization with nano-metallic $\mathrm{Ca} / \mathrm{CaO}$ dispersion mixture by grinding. The leachable heavy metals concentrations were reduced, after nano-metallic $\mathrm{Ca} / \mathrm{CaO}$ treatment to a concentration lower than the Japan soil elution standard regulatory threshold. SEM-EDS elements map as well as semi- quantitative analysis, observed that the amount of $\mathrm{As}, \mathrm{Cd}, \mathrm{Cr}$ and $\mathrm{Pb}$ detectable on soil particle surface decreases after nano-metallic $\mathrm{Ca} / \mathrm{CaO}$ treatment. The results suggest that nano metallic $\mathrm{Ca} / \mathrm{CaO}$ mixture is a suitable treatment for the gentle immobilization of heavy metals in polluted soil. The addition of nano-metallic $\mathrm{Ca} / \mathrm{CaO}$ that enhanced heavy metals immobilization in soil at normal moisture conditions is an innovative approach for the remediation of soils polluted with heavy metals.

\section{Acknowledgements}

Authors thankful to New Energy and Industrial Technology Development Organization (NEDO) Program (Project ID: 09B35003a)" for providing financial support for this study.

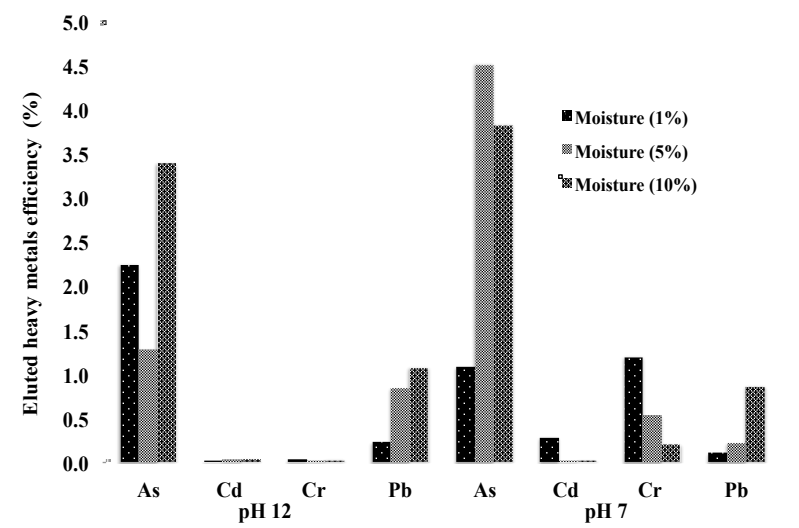

Fig. 1. Eluted heavy metals efficiency in soil with various moisture and at $\mathrm{pH}$ conditions after nano- $\mathrm{Ca} / \mathrm{CaO}$ treatment.

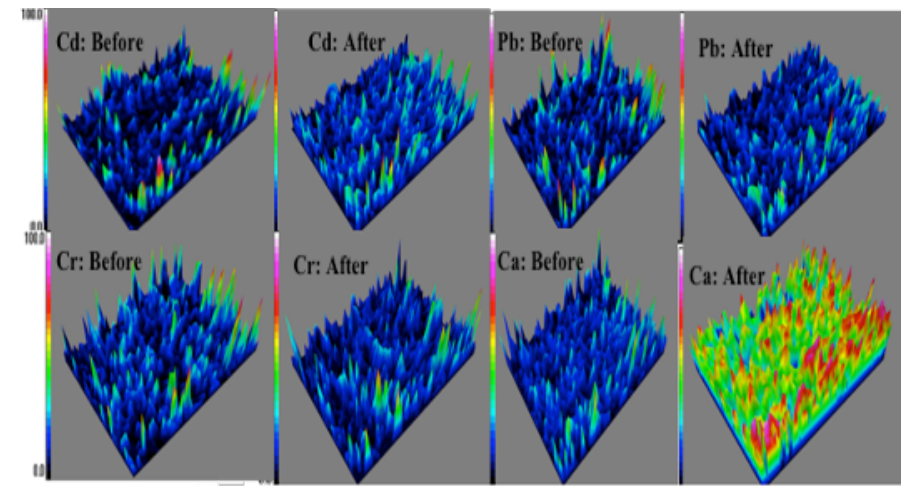

Fig. 2. SEM-EDS 3D elements map of heavy metals contaminated soils before and after nano-metallic $\mathrm{Ca} / \mathrm{CaO}$ treatment. 


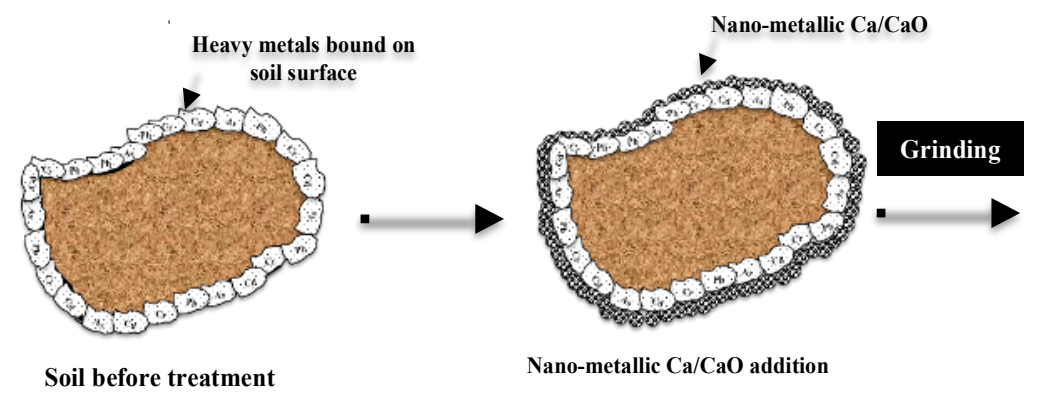

a: Heavy metals adsorption and nano-metallic $\mathrm{Ca} / \mathrm{CaO}$ addition on soil

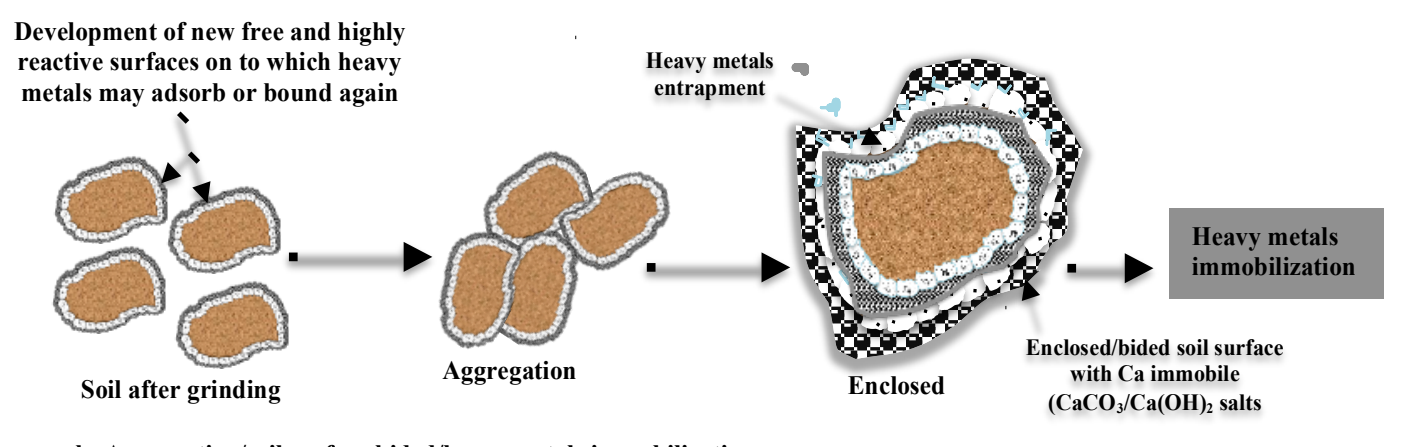

b: Aggregation/soil surface bided/heavy metals immobilization

Fig. 3. Schematic representation of possible mechanisms which may determine the enhanced heavy metals immobilization efficiency in soil after grinding with nano-metallic $\mathrm{Ca} / \mathrm{CaO}$ : (a) heavy metals adsorption and nano-metallic $\mathrm{Ca} / \mathrm{CaO}$ addition; (b) aggregation and surface bided.

\section{References}

Lin, CF, Lo SS, Lin HY, Lee YC. Stabilization of cadmium contaminated soilsusing synthesized zeolite. J Hazardous Materials 1998; 60:217-226.

Macauley, E., Hong, A., Chelation extraction of lead from soil using pyridine-2,6-dicarboxylic acid. J Hazardous Materials 1995; 40, 257-270.

Ministry of Environment Government of Japan. Soil Contamination Countermeasures Law Enforcement Regulation, 2002, Ordinance No. 29.

Ministry of Environment Government of Japan. Matters providing for measurement method of soil elution test, , 2003, Notification No. 18.

Mitoma Y, Miyata H, Egashira N, Simion A, Kakeda M, Simion C. Mechanochemical degradation of chlorinated contaminants in fly ash with a calcium-based degradation reagent. Chemosphere 2011; 83:1326-1330.

Montinaro S, Concas A, Pisu M, Cao G. Remediation of heavy metals contaminated soils by ball milling. Chemosphere 2007; 67:631-639.

Paff SW, Bosilovich BE. Use of lead reclamation in secondary lead smelters for the remediation of lead contaminated sites. J Hazardous Materials 1995; 40, 139-164.

Reddy, KR., Xub CY, Chinthamreddy S. Assessment of electrokinetic removal of heavy metals from soils by sequential extraction analysis. J Hazardous Materials 2001; 84: 27-296.

Srinivasa Reddy M, Mitoma Y, Okuda T, Sakita S, Kakeda M. High immobilization of soil cesium using ball milling with nano-metallic $\mathrm{Ca} / \mathrm{CaO} / \mathrm{NaH} 2 \mathrm{PO} 4$ : implications for the remediation of radioactive soils. Environmental Chemistry Letters 2012; DOI: 10.1007/s10311-012-0357-3.

USEPA. Guide to the disposal of chemically stabilized and solidified waste, SW-872. Office of Water and Waste Management, Washington DC, 1982. 